\title{
Fenomena perilaku bullying di sekolah
}

\author{
Hariyanto Wibowo ${ }^{1 *}$, Fijriani Fijriani ${ }^{2)}$, Veno Dwi Krisnanda ${ }^{3)}$ \\ 1,2,3) Universitas Indraprasta PGRI \\ *) hariyantowibowo571@gmail.com
}

Article History:

Received: $03 / 08 / 2021$

Revised: 19/10/2021;

Accepted: 22/10/2021

Published: 30/10/2021.

How to cite:

Wibowo, H., Fijriani, F., \&

Krisnanda, V.D. (2021).

Fenomena perilaku bullying di sekolah. Orien: Cakrawala Ilmiah

Mahasiswa, 1(2), pp. 157-166.

DOI: $10.30998 /$ ocim.v1i2.5888

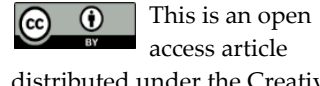

distributed under the Creative

Commons 4.0 Attribution

License, which permits

unrestricted use, distribution,

and reproduction in any

medium, provided the original

work is properly cited. (C) 2021,

Wibowo, Fijriani, \& Krisnanda.

\begin{abstract}
Abstrak: tujuan penelitian adalah untuk mengetahui bagaimana fenomena perilaku bullying pada siswa di sekolah. Penelitian ini merupakan penelitian kualitatif dengan studi pustaka. Teknik analisis data dalam penelitian ini adalah menggunakan analisis deskriptif. Penelitian ini terdiri dari sumber primer 20 artikel yang tertuang dalam hasil penelitian. Pencarian literature review sesuai dengan protocol PRISMA ditemukan 12.200 artikel. Tahap kedua artikel yang sudah di screening di temukan 9760 artikel dengan tahun publikasi 2015-2020. Kemudian di tahap terakhir dilakukan studi kelayakan untuk mengeiminasi duplikasi artikel sebanyak 648 dan artikel sehingga di dapatkan sebanyak 20 artikel. Berdasarkan hasil screening ditemukan 20 artikel sesuai dengan protocol PRISMA. Dalam literature review diperoleh bahwa self-efficacy merupakan tingkat kepercayaan seseorang pada kemampuan sendiri untuk menyelesaikan tugas dan mencapai tujuan, telah dibuktikan sebagai faktor pencegahan yang efektif untuk kasus bullying di sekolah. Sebagai keprihatinan global, self-eficacy pada korban bullying dapat memberikan keyakinan bahwa dirinya mampu mengatasi berbagai permasalahan psikologi.
\end{abstract}

Kata Kunci: bullying

Abstract: the purpose of the study was to find out how the phenomenon of bullying behavior in students at school. This research is a qualitative research with literature study. The data analysis technique in this research is using descriptive analysis. This research consists of primary sources of 20 articles contained in the research results. A literature review search according to the PRISMA protocol found 12,200 articles. The second stage of the articles that have been screened found 9760 articles with the publication year 2015-2020. Then in the last stage a feasibility study was carried out to eliminate duplicate articles as many as 648 and articles so that as many as 20 articles were obtained. Based on the results of the screening, 20 articles were found according to the PRISMA protocol. In a literature review, it was found that selfefficacy is a person's level of confidence in his own ability to complete tasks and achieve goals, has been proven as an effective prevention factor for cases of bullying in schools. As a global concern, self-efficacy for victims of bullying can provide confidence that they are able to overcome various psychological problems.

Keywords: bullying

\section{Pendahuluan}

Permasalahan bullying di institusi pendidikan Indonesia bukan sebuah kasus baru. Berita tentang kasus bullying ini terjadi di sekolah dapat dilihat atau baca di media massa. Kasus bullying yang diberitakan berbagai macam antara lain yang dilakukan oleh kakak kelas terhadap adik kelasnya maupun antarteman sekelas. Banyaknya kasus kekerasan yang terjadi pada anak 
usia sekolah saat ini sangat memprihatinkan bagi pendidikan maupun orang tua. Sekolah yang seharusnya menjadi tempat untuk menimba ilmu serta membantu membentuk kepribadian yang positif ternyata dijadikan tempat untuk perundungan.

Survei yang dilakukan oleh Plan Indonesia dan Semai Jiwa Amini (SEJIWA) pada tahun 2008, membuktikan bahwa tindak bullying pernah terjadi di sekolah. Survei ini melibatkan 1.500 siswa SMP dan SMA di tiga kota besar di Indonesia yakni Jakarta, Surabaya dan Yogyakarta, yang mencatat terjadinya tingkat kekerasan sebesar 67.9 persen di tingkat SMA dan 66,1 persen di tingkat SMP. Bullying tercatat sebesar 43,7 persen untuk tingkat SMA dan 41,2 persen untuk tingkat SMP, dengan kategori tertinggi bullying secara psikologis berupa pengucilan. Peringkat kedua ditempati bullying secara verbal berupa ejekan, dan terakhir bullying secara fisik berupa pukulan.

Data Komisi Perlindungan Anak Indonesia (KPAI) dari tahun 2011 sampai Agustus 2014, tercatat 369 pengaduan terkait masalah bullying. Jumlah itu sekitar 25\% dari total pengaduan di bidang pendidikan sebanyak 1.480 kasus. Bullying yang disebut KPAI sebagai bentuk kekerasan di sekolah mengalahkan tawuran pelajar, diskriminasi pendidikan, ataupun aduan pungutan liar. Berbagai cara dilakukan untuk meminimalisir kejadian bullying di sekolah termasuk salah satunya Komnas Perlindungan Anak mendesak ke pihak sekolah untuk lebih melindungi dan memperhatikan murid-muridnya. Sedangkan tindakan bullying hanyalah bagian dari cara anakanak bermain. Tidak ada peraturan khusus yang mewajibkan sekolah harus memiliki kebijakan program anti bullying, tetapi dalam Undang-Undang Nomor 23 Tahun 2002 Tentang Perlindungan Anak, Pasal 54 ditentukan "Anak di dalam dan di lingkungan sekolah wajib dilindungi dari tindakan kekerasan yang dilakukan oleh guru, pengelola sekolah atau temantemannya di dalam sekolah yang bersangkutan, atau Lembaga pendidikan lainnya".

Bullying harus segera dihilangkan karena dapat menyebabkan efek yang sangat serius baik dalam jangka pendek maupun jangka panjang bagi para korbannya. Dalam jangka pendek bullying dapat menimbulkan luka akibat kekerasan fisik, menimbulkan perasaaan tidak aman, takut pergi ke sekolah, merasa terisolasi. Anak-anak yang diganggu sering menderita akademis karena bahwa mereka takut pergi ke sekolah di mana sekolah adalah sumber stres dan ketakutan mereka. Sedangkan dalam jangka panjang hingga berlangsung efek seumur hidup pada korban, korban bullying dapat menderita masalah gangguan emosional dan perilaku seperti perasaan harga diri yang rendah, ketidakmampuan bersosialisasi, depresi, bahkan dapat berakhir dengan bunuh diri bagi korban.

Tattum, Delwyn \& Herbert (1993) mengungkapkan ditemukan bahwa anak-anak yang menjadi korban bullying memiliki harga diri yang rendah, dan melihat diri mereka dalam hal negatif menjadi beberapa masalah, lebih cemas, popular, dan kurang bahagia dibandingkan anak-anak yang tidak pernah diganggu. Tindakan Bullying di kalangan pelajar sangat mengganggu kesehatan mental bagi pelakunya juga, dan akan berpengaruh pada kehidupan dewasa yang akan dijalaninya. Pelaku bullying akan merasa lebih memiliki rasa percaya yang tinggi dan dapat menimbulkan perilaku yang mengarah pada tindak kekerasan. Perilaku bullying yang tidak ditangani dengan baik pada masa anak-anak justru dapat menyebabkan gangguan perilaku yang lebih serius di masa remaja dan dewasa, seperti: pelecehan seksual, kenakalan remaja, keterlibatan dalam geng kriminal, pelecehan atau bullying ditempat kerja, kekerasan dalam rumah tangga, pelecehan/kekerasan terhadap anak, kekerasan terhadap orang tua sendiri.

Pada kasus bullying ini perlu ditangani khusus oleh seluruh elemen masyarakat dan pihak sekolah khususnya pada program layanan bimbingan dan konseling. Sekolah yang seharusnya menjadi tempat bagi anak menimba ilmu serta membantu membentuk karakter pribadi yang positif ternyata malah menjadi tempat tumbuhnya praktek-praktek bullying. Layanan Bimbingan 
dan Konseling (BK) di sekolah wajib diberikan kepada siswa dengan optimal dalam pencegahan perilaku bullying, namun kenyataan yang terjadi di sekolah sekarang tampak bahwa beberapa konselor bukan lulusan BK sehingga pemberian layanan tidak secara penuh terlaksana dengan baik.

Akibat dari pemberian layanan BK yang kurang optimal ini maka masih banyak ditemukan kasus-kasus bullying yang marak terjadi di lingkungan sekolah. Para remaja tidak dapat mengontrol dirinya, dalam pengambilan keputusan tidak tepat, tidak bisa mengorganisasikan dirinya sesuai dengan keadaan yang terjadi, tidak mempunyai kepekaan dan norma perilaku dalam masyarakat. Bullying terjadi bukan karena kemarahan, atau karena adanya konflik yang harus diselesaikan. Bullying lebih pada perasaan superior, sehingga seseorang merasa memiliki hak untuk menyakiti, menghina, atau mengendalikan orang lain yang dianggap lemah, rendah, tidak berharga, dan tidak layak untuk mendapatkan rasa hormat.

Bullying menurut Komnas HAM (Hak Asasi Manusia) adalah sebagai suatu bentuk kekerasan fisik dan psikologis berjangka Panjang yang dilakukan seseorang atau kelompok terhadap seseorang yang tidak mampu mempertahankan diri dalam situasi ada hasrat untuk melukai atau menakuti orang atau membuat orang tertekan, trauma atau depresi dan tidak berdaya. Kebiasaan pengeroyokan sebagai bentuk main hakim sendiri dalam menyelesaikan pertikaian atau konflik juga tampak sangat kuat di kalangan pelajar. Fenomena bullying bisa juga diartikan sebagai perbuatan atau perkataan seseorang kepada orang lain yang dapat menimbulkan rasa takut, sakit dan tertekan baik secara fisik maupun mental yang telah direncanakan oleh pihak yang lebih kuat dan berkuasa terhadap pihak yang dianggap lebih lemah darinya. Bullying biasanya dilakukan dengan alasan pembentukan mental si yunior. Tetapi, bullying biasanya terjadi atas dasar "balas dendam" si senior karena mereka juga pernah menjadi korban bullying senior sebelum mereka. Akibat dari perilaku tersebut banyak siswa yang merasa terkucil, sehingga ia selalu merasa gelisah ketika bertemu dengan orang lain.

Bullying tidak juga hanya dilakukan dengan kekerasan, melainkan bisa juga dilakukan dengan mengejek, memaki, menghakimi dan menggosipi orang lain. Dan beberapa korban bullying memiliki karakter yang berbeda dengan yang lainnya, seperti selalu cemas, tidak percaya diri, dan memiliki kemampuan bersosialisasi yang kurang. Siswa mempunyai hak untuk mendapat pendidikan dalam lingkungan yang aman dan bebas dari rasa takut. Pengelola Sekolah dan pihak lain yang bertanggung jawab dalam penyelengaraan Pendidikan mempunyai tugas untuk melindungi siswa dari intimidasi, penyerangan, kekerasan atau gangguan. Tindakan bullying mengakibatkan konsentrasi siswa berkurang, kehilangan percaya diri, stress dan sakit hati, trauma berkepanjangan, membalas bullying, merasa tidak berguna, kasar dan dendam, berbohong dan takut kesekolah. Penelitian ini bertujuan untuk mendeskripsikan dan menganalisis fenomena bullying yang terjadi di sekolah untuk dilihat dari sudut pandang pergaulan antar siswa, tanggapan sekolah, perilaku dari korban, pelaku, dan penonton serta upaya sekolah dalam menanganinya.

\section{Metode}

Penelitian ini merupakan penelitian dengan menggunakan literatur review. Data yang digunakan dalam penelitian ini adalah data sekunder. Sumber data sekunder yang dimaksud berupa buku dan laporan ilmiah primer atau asli yang terdapat di dalam artikel atau jurnal (tercetak dan/atau non-cetak). Pemilihan sumber didasarkan pada empat aspek yakni:(1) Provenance (bukti), yakni aspek kredensial penulis dan dukungan bukti, misalnya sumber utama sejarah; (2) Objectivity (Objektivitas), yakni apakah ide perspektif dari penulis memiliki banyak 
kegunaan atau justru merugikan; (3) Persuasiveness (derajat keyakinan), yakni apakah penulis termasuk dalam golongan orang yang dapat diyakini; dan (4) Value (nilai kontributif),

Penelitian ini terdiri dari sumber primer 20 jurnal yang tertuang dalam hasil penelitian. Pencarian literatur review sesuai dengan protocol PRISMA ditemukan 12.200 artikel (250 Pro Quest, 176 EBSCO, 324 DOAJ, 11.101 Google Scholar, 349 Research Gate). Tahap kedua artikel yang sudah di-screening ditemukan 9760 artikel dengan tahun publikasi 2015-2020. Screening jurnal fulltext artikel didapatkan sejumlah 1.140 dari artikel yang hanya berisi abstrak sebanyak 844, teks tidak full sebanyak 209, nonbahasa Indonesia dan bahasa Inggris sebanyak 247 artikel. Kemudian di tahap terakhir dilakukan studi kelayakan (elligility) untuk mengeliminasi duplikasi artikel sebanyak 648 dan artikel sehingga di dapatkan sebanyak 20 artikel.

\section{Hasil dan Diskusi}

Penelitian ini terdiri dari sumber primer 20 jurnal yang tertuang dalam hasil penelitian. Pencarian literatur review sesuai dengan protocol PRISMA ditemukan 12.200 artikel (250 Pro Quest, 176 EBSCO, 324 DOAJ, 11.101 Google Scholar, 349 Research Gate). Tahap kedua artikel yang sudah di screening di temukan 9760 artikel dengan tahun publikasi 2015- 2020. Screening jurnal fulltext artikel diperoleh sejumlah 1.140 dari artikel yang hanya berisi abstrak sebanyak 844 , teks tidak full sebanyak 209, nonbahasa Indonesia dan bahasa Inggris sebanyak 247 artikel. Kemudian di tahap terakhir dilakukan studi kelayakan (elligility) untuk mengeiminasi duplikasi artikel sebanyak 648 dan artikel sehingga di dapatkan sebanyak 20 artikel.

Tabel 1 Protokol PRISMA (Preffered Reporting Items for Systematic Review and Meta Analyses)

\begin{tabular}{|c|c|c|c|c|c|c|}
\hline$\stackrel{8}{8}$ & Proquest & EBSCO & DOAJ & $\begin{array}{l}\text { Google } \\
\text { Scholar }\end{array}$ & $\begin{array}{l}\text { Research } \\
\text { Gate }\end{array}$ & Keterangan \\
\hline$\underset{2}{2}$ & $N=250$ & $\mathrm{~N}=176$ & $=24$ & $\mathrm{~N}=11.101$ & $\mathrm{~N}=349$ & $\begin{array}{l}\text { Artikel yang didapatkan } \\
\qquad \mathrm{N}=12.200\end{array}$ \\
\hline \multicolumn{7}{|c|}{ Artikel yang didapatkan $\mathrm{N}=12.200$} \\
\hline \multirow{3}{*}{ 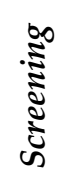 } & \multicolumn{5}{|c|}{ Tahun Publikasi 2015-2020 } & \\
\hline & $\mathrm{N}=147$ & $\mathrm{~N}=138$ & $=94$ & $\mathrm{~N}=9044$ & $N=237$ & $\begin{array}{l}\text { Artikel Tahun Publikasi 2015-2020 } \\
(\mathrm{N}=9760)\end{array}$ \\
\hline & \multicolumn{5}{|c|}{$\mathrm{N}=2.440$} & \\
\hline \multirow[b]{4}{*}{ 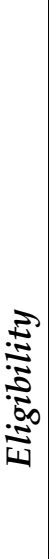 } & & & Fulltext & rtikel & & Hanya abstrak $(\mathrm{N}=844)$ \\
\hline & \multirow{2}{*}{\multicolumn{5}{|c|}{$\mathrm{N}=1.140$}} & Teks tidak full $(\mathrm{N}=209)$ \\
\hline & & & & & & $\begin{array}{l}\text { Non bahasa inggis }(\mathrm{N}=247 \text { bahasa } \\
\text { korea) }\end{array}$ \\
\hline & \multicolumn{5}{|c|}{$\begin{array}{l}\text { Screening pada duplikasi, judul, kriteria inklusi dan } \\
\text { kriteria eksklusi, dan relevan } \\
\qquad \mathrm{N}=20\end{array}$} & $\begin{array}{l}\text { Duplikasi }(\mathrm{N}=468) \\
\text { Kriteria Inklusi }(\mathrm{N}=324) \\
\text { Kriteria Eksklusi }(\mathrm{N}=328)\end{array}$ \\
\hline
\end{tabular}




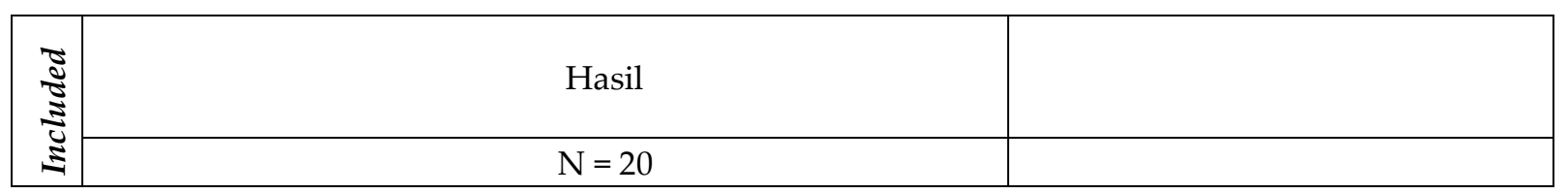

Dalam literature review menurut Cao et al., (2018) bahwa self-efficacy merupakan tingkat kepercayaan seseorang pada kemampuan sendiri untuk menyelesaikan tugas dan mencapai tujuan, telah dibuktikan sebagai faktor pencegahan yang efektif untuk kasus bullying di sekolah. Selain itu, sebagai keprihatinan global, self-eficacy pada korban bullying dapat memberikan keyakinan bahwa dirinya mampu mengatasi berbagai permasalahan psikologi, seperti agresi, melukai diri sendiri, dan kecemasan. Guru juga diharapkan dapat memotivasi dengan cara Selfefficacy dalam diri korban bullying yang merasa rendah diri dapat meningkatkan kepercayaan dirinya (Rahman et al., 2017).

Korban bullying sering enggan melaporkan insiden bullying karena mereka takut akan diberi label, mereka pikir itu akan merperburuk situasi, atau mereka mereka menganggap bahwa guru dan juga guru BK tidak dapat atau menghentikan bullying di sekolah (lee jun choi et al., 2015). Jika perilaku bullying terus terjadi dampak yang akan dialami korban bullying adalah berbagai macam gangguan yang meliputi kesejahteraan psikologi rendah (low psychology wellbeing) dimana korban bullying merasa tertekan, tidak nyaman, takut, murung, rendah diri, dan merasa tidak berharga, lalu menjauh dari temantemannya, menjadi pendiam, sulit tidur nyenyak, serta menjadi pengguna obat-obatan terlarang (Zakiyah, E. Z et al., 2019).

Perilaku bullying menimbulkan dampak bagi pelaku dan korban. Dampak bullying tehadap kesehatan mental korban meliputi rasa marah yang meluap-luap, depresi, rendah diri, cemas, kualitas tidur menurun, nafsu makan menurun, keinginan menyakiti diri sendiri, hingga bunuh diri. Bullying bagian dari perilaku agresi dimana terjadi ketidakseimbangan kekuatan dan kekuasaan antara pelaku. Dalam jurnal The Psychological Effect of Bullying Last Well Into Adulthood, Study Finds (2019) mengungkapkan bahwa korban bullying memiliki resiko tinggi mengalami gangguan depresi, gangguan kecemasan, generalized anxiety disorder (kecemasan kronis ditandai dengan rasa khawatir dan tegang yang berlebihan), dan agoraphobia (ketakutan dasar yang berasal dari perasaan terjebak di tempat umum, saat seseorang merasa sulit melakukan diri, dan rasa takut tidak akan tersedianya pertolongan apabila seseorang serangan panik) pada saat dewasa.(Utami, T. W, et al.,2019).

Individu yang memiliki efikasi diri yang baik akan selalu berpegang teguh terhadap tujuannya, begitu juga sebaliknya individu yang memiliki efikasi diri yang kurang baik akan memiliki komitmen yang rendah terhadap tujuannya. Kokkinos, C. M. et al, dalam reviewnya mengungkapkan bahwa self-efficacy yang dirasakan dapat menyesuaikan hubungan antara bullying/korban bullying dan penanggulangannya. Ketika orang dihadapkan pada situasi yang penuh tekanan, mereka yang menganggap diri mereka mampu dan efisien menunjukkan lebih banyak upaya untuk mengatasi masalah, sedangkan mereka yang menganggap diri mereka tidak mampu dan tidak efisien tunduk dengan mudah, merasa tertekan, cemas, dan putus asa dan cenderung menggunakan koping yang disfungsional (Kokkinos et al., 2015).

Literature review ini memiliki banyak keterbatasan antara lain karena skala yang diambil tidak membatasi negara atau benua, pembatasan jumlah sampel, sehingga hasil memberikan heterogenitas yang terlalu tinggi. Selain itu penulis tidak membatasi desain studi kuantitatif dengan maksud mendapatkan lebih banyak informasi yang dapat digali. Review ini bermanfaat untuk mengatasi masalah kesehatan mental anak yang dialami korban bullying setelah mendapat tindakan bullying seperti kekerasan, diejek teman sebaya, dan mengancam. Beberapa dampak 
peristiwa bullying yang dialami korban bullying terhadap psikologinya seperti sering murung, anak menjadi lebih pendiam, mengurung diri, menangis setelah pulang sekolah, merasa kesulitan tidur, selalu merasa gelisah, depresi bahkan sampai bunuh diri jika tidak diatasi dengan cepat. Oleh karena itu, self-efficacy memiliki peranan penting dalam penyelesaian kesehatan mental korban bullying. Perawat diharapkan dapat menjadi konselor bagi korban bullying untuk meningkatkan self-efficacy agar individu tersebut bisa lebih percaya diri dan mengambil mekanisme koping yang tepat. Self-efficacy yang tinggi memiliki keyakinan bahwa dirinya mampu mengatasi masalah bullying yang dialaminya.

\section{Simpulan}

Berdasarkan hasil penelitian pustaka yang telah dilakukan oleh peneliti, maka dapat ditarik kesimpulan bahwasanya dalam menghadapi siswa korban perilaku bullying, konselor harus menangani sejumlah masalah besar baik yang ada sekarang maupun di masa lalu. Kemarahan dan perasaan dikhianati di pihak korban bullying sering kali harus ditangani dahulu sebelum menghadapi keluarga sebagai satu kesatuan untuk mengoreksi masalah dan mencegah agar tidak terjadi lagi. Lebih jauh lagi, karena melibatkan masalah hukum, korban kekerasan mungkin dipisahkan dari keluarga, yang membuat tugas menangani keluarga menjadi jauh lebih sulit dan menantang.

Fenomena bullying antara siswa memang perlu diperhatikan lebih lanjut. Dari alasan alasan pelaku melakukan tindakan bullying itu sendiri apakah terjadi masalah antara pelaku dan korban sehingga tidak bisa diselesaikan secara baik baik, atau terjadi karena faktor lingkungan pelaku yang membuat perilaku bullying melekat didalam diri pelaku itu sendiri. Karena didalam penelitian atau analisa jurnal dalam studi pustaka tidak bisa diperlihatkan secara langsung dan hanya bisa dilihat dari persepsi peneliti dan hanya persenan angka saja. Untuk menindak lanjuti perilaku bullying tersebut sebagai konselor atau Guru BK harus bisa membimbing pelaku agar tidak mengulang kesalahan yang sudah diperbuat. Agar pelaku menyadari bahwa tindakannya salah, sebagai konselor atau Guru BK harus bisa memberikan contoh yang baik dan dapat diterima oleh pelaku tersebut. Lalu untuk korban perilaku bullying, harus diperhatikan kondisi mental dan diberikan kegiatan-kegiatan positif yang dapat membuat kondisi korban menjadi membaik.

\section{Ucapan Terima Kasih}

Pada kesempatan yang baik ini, izinkanlah penulis menyampaikan rasa hormat dan ucapan terima kasih kepada semua pihak yang dengan tulus ikhlas telah memberikan bantuan dan dorongan kepada penulis dalam menyelesaikan skripsi ini, terutama kepada Ibu Fijriani, M.Pd. Kons., selaku Dosen Pembimbing Materi, Bapak Veno Dwi Krisnanda, M.Pd. selaku Dosen Pembimbing Teknik, Prof. Dr. H. Sumaryoto, Rektor Universitas Indraprasta PGRI, Dr. H. Taufik, S.Pd., M. Hum, Dekan Fakultas Ilmu Pendidikan dan Pengetahuan Sosial, Ibu Sabrina Dachmiati, M.Pd. Kons., selaku Ketua Program Studi Bimbingan dan Konseling, Seluruh Bapak/Ibu Dosen serta Staff Tata Usaha di Universitas Indraprasta PGRI, Kepada alm. Bapak dan Mama saya yang selalu mendukung dan tak pernah lelah mendo'akan saya, Kepada saudari sepupu saya Marsella Anggitafani Setiawan yang telah banyak membantu saya dalam berpikir dalam proses penelitian ini, Semua pihak yang tidak dapat disebutkan satu per satu, yang telah memberikan bantuan dan dukungan serta semangat kepada saya dalam rangka penyelesaian penelitian ini. 


\section{Daftar Rujukan}

Achmad Maulana, (2011). Kamus Ilmiah Populer Lengkap, Yogyakarta: Absolut

Anas Sudijono, (2004). Pengantar Evaluasi Pendidikan, Yogyakarta: Jakarta Rajawali Perss

Andi Dewa Ketut Sukardi, 2008. Pengantar Pelaksanaan Program Bimbingan dan Konseling Jakarta, Rieneka Cipta Ehan, “Bullying dalam pendidikan”, Jurnal Ilmu

Arikunto, Suharsimi. (2002). Prosedur Suatu Pendekatan dan Praktek. Jakarta: Rhineka Cipta.

Astuti, P. Retno. (2008). Meredam Bullying: 3 Cara Efekif Menanggulangi Kekerasan pada Anak. Jakarta: Kompas Gramedia

Baron dan Bryne. (2015). Psikologi Sosial. Jakarta: Erlangga.

Basrowi dan Suwandi, (2008). Memahami Penelitian Kualitatif, Jakarta: Rineka Cipta

Benatov, J. (2019). Parents' Feelings, Coping Strategies and Sense of Parental SelfEfficacy When Dealing With Children's Victimization Experiences. Frontiers.

Bimo Walgito, (2004). Bimbingan dan Konseling di Sekolah,Yogyokarta

Bingöl, T. Y. (2018). The predictive role of selfefficacy, gender, and cyber victimization on cyber bullying in adolescents. Universal Journal of Educational Research, 6(11), 2478-2483

Burhan, Bungin. (2003). Metodologi Penelitian Kualitatif, Jakarta: Raja Grafindo Persada.

Cao, Y., \& Yang, F. (2018). Self-Efficacy and Problem Behaviors of School Bully Victims: Evidence from Rural China. Journal of Child and Family Studies

Choi, L. J. (2016). School Counsellor s ' SelfEfficacy In Dealing With Bullying Among Secondary School Students. October 2015

Coloroso, Barbara. (2013). Stop Bullying (Memutus Rantai Kekerasan Anak dari Prasekolah Hingga SMU. Jakarta: Serambi Ilmu Semesta. Counseling), Bandung: Ilmu

Dayakisni, T. Yuniardi. (2011). Psikologi Sosial. Malang: UMM Press

Denney, A. S., \& Tewksbury, R. (2013). How to write a literature review. Diperoleh 22 juli 2021

D, Rizky. (2012). Pemanfaatan Open Source Software Pendidikan Oleh Mahasiswa Dalam Rangka Implementasi Undang-undang No. 19 Dampak bullying Terhadap Kesehatan mental Anak. (2020, October 5).

Emzir. (2010). Metodologi Penelitian Pendidikan: Kuantitatif dan Kualitatif. Jakarta: Rajawali Pers

Etta Mamang Sangadji dan Sopiah, 2010. Metodelogi Penelitian Pendekatan Praktis dalam Penelitian, Yogyakarta.

Fajrul (2019, Oktober 10). Kenapa Bullying Bahaya dan Seharusnya Tidak Perlu Kamu Lakukan. Retrieved Oktober 10, 2019.

Geldard, Kathryn. (2012). Konseling Remaja: Intervensi Praktis Bagi Remaja Beresiko. Yogyakarta: Pustaka Pelajar

Ginanjar, A. S. (2017). Masa Galau Remaja Autistik. Bogor: Grafika Mardi Yuana Grafindo.

Guimond, F. A., Brendgen, M., Vitaro, F., Dionne, G., \& Boivin, M. (2015). Peer victimization and anxiety in genetically vulnerable youth: The protective roles of teachers' self-efficacy and 
anti-bullying classroom rules. Journal of Abnormal Child Psychology, 43(6), $\quad$ 10951106. https://doi.org/10.1007/s10802-015-0001-3

Gunawan, Imam. (2013). Metode Penelitian Kualitatif. Teori dan Praktik. Jakarta: PT Bumi Aksara.

Handayani, N. F., \& Lisnawati. (2019). I CARE Training to Increase the Self-Efficacy and Prosocial Behavior of Students Observers of Bullying. 229(Iciap 2018), 753-769. https://doi.org/10.2991/iciap-18.2019.63

Haraldstad K, Kvarme L, Christophersen K, \& Helseth S. (2019). Associations between selfefficacy, bullying and health-related quality of life in a school sample of adolescents: a cross-sectional study. BMC Public Health [revista en Internet] 2019 [acceso 20 de junio de 2019]; 19(1): 1-9. BMC Public Health, 19(1), 1-9. https://doi.org/10.1186/s12889-019-7115$\underline{4}$

Haris Herdiansyah, (2011). Metodologi Penelitian Kualitatif Untuk IlmuSosial, Jakarta: Salemba Humanika

Hariwijaya \& Bisri M. Djaolani, 2004. Pedoman Menyusun Skripsi dan Tesis, Yogyakarta: Siklus Hartono,1996.Kamus Praktik Bahasa Indonesia, Jakarta: Rineka Cipta, Hasilstudi yang dilakukan National Youth Violence Prevention Resource Center Sanders (2003)

Hassan, A., Reda Shehata Elsayed2, K., \& Elsayed, W. A. (2015). Bullying Behaviors and Self Efficacy among Nursing Students at Clinical Settings: Comparative Study. Journal of Education and Practice, 6(35), 25-36. https://doi.org/doi:10.2147/AMEP.S75830

Hibana S. Rahman, (2003). Bimbingan Konseling Pola 17, Yogyakarta: Uci Press

Hibualamo, (2017). Peran Konselor Dalam Mengurangi Perilaku Bullying. Jurnal Hibualamo. No 1(1) ISSN: 2549-7030

Hsieh, Y. H., Wang, H. H., \& Ma, S. C. (2019). The mediating role of self-efficacy in the relationship between workplace bullying, mental health and an intention to leave among nurses in Taiwan. International Journal of Occupational Medicine and Environmental Health, 32(2), 245-254. https://doi.org/10.13075/ijomeh.1896.01322

Ilmiah, J. P. (2017). Program Psikoeduasi Bullying Untuk Meningkatkan Efikasi Diri Guru Dalam Menangani Bullying Di Sekolah Dasar. Intuisi: Jurnal Psikologi Ilmiah, 9(3), 258266.Journal of criminal justice education, 24(2), 218-234.

Jovee.id. Retrieved November 24, 2020, from https://jovee.id/dampak-bullyingterhadapkesehatan-mental-dan-fisik-anak/

Kasiram, Mohammad. (2008), Metode Penelitian Kuantitatif-Kualitatif. Malang: UIN-Malang Press Munggaran

Kokkinos, C. M., Panagopoulou, P., Tsolakidou, I., \& Tzeliou, E. (2015). Coping with bullying and victimisation among preadolescents: the moderating effects of self-efficacy. Emotional and Behavioural Difficulties, 20(2), 205-222. https://doi.org/10.1080/13632752.2014.955

Lexy J. Moleong, 2005. Metodologi Penelitian Kualitatif, Bandung: Remaja Rosdakarya 
Liberati, A., Petticrew, M., ... PGroup, T. (2016). Preferred reporting items for systematic review and meta-analysis protocols (PRISMAP) 2015: elaboration and explanation. BMJ, 354, i4086. https://doi.org/10.1136/bmj.i4086

Marchant, R. (2016). Relational Bullying, Gender, and Interpersonal Self-Efficacy in Young Adults. 41. National Centre Against bullying. 2019.

Malm, E. K., Henrich, C., Varjas, K., \& Meyers, J. (2017). Parental Self-Efficacy and Bullying in Elementary School. Journal of School Violence, 16(4), 411-425. https://doi.org/10.1080/15388220.2016.1168743

Margono. (2007). Metodologi Penelitian Pendidikan. Jakarta: Rineka Cipta.

M. Djunaidi Ghony \& Fauzan Almanshur. 2012. Metodelogi Penelitian Kualitatif, Jogjakarta: ArRuzz Media

Nursahid. (2014). Program Pembelajaran Tilawah Qur'an Pada PondokPesantren Al Qur'an Al Falah https://doi.org/10.3389/fpsyt.2019.00700

Prayitno, (2004). Dasar-dasar Bimbingan dan Konseling. Jakarta: Rineka Cipta.

Rahman, H. F., Yulia, \& Sukamarini, L. (2017). Efikasi Diri, Kepatuhan, dan Kualitas Hidup Pasien Diabetes mellitus Tipe 2. Jurnal Pustaka Kesehatan.

Retno Astuti, (2008). Meredam bullying, Grasindo. Kompas Gramedia.

Robiah, Jurnal saintech: mengurangi perilaku bullying kels X-4 melalui Pemberian layanan bimbingan kelompok dan tehnik role playing di SMA negeri 12 Medan.

Sekolah dan Lingkungan Anak. Jakarta: Grasindo www.kompas.CegahBullyingSejakDini.htm. http://repository.unimus.ac.id

Siti Nurbaiti, (2009). "Peran Guru Bimbingan dan Konseling dalam Mengatasi Perilaku Bullying di Sekolah SMA Al-Izhar Pondok Labu". Skripsi. Jakarta: Universitas Islam Negeri Syarif Hidayatullah Jakarta.

Shafie, A. A. H. Bin, Miskam, N. A. B. A., Rozubi, N. B. C., \& Anuar, A. A. Bin. (2018). Enhancing the Self-Efficacy and Assertiveness Level Among the Bullied Victim School Students By Using Cognitive Behaviour Theraphy (CBT) in Group Counselling Approach. International Journal of Academic Research in Business and Social Sciences, 8(1), 300-313. https://doi.org/10.6007/ijarbss/v8-i1/3809

Soetjipto, Helly Prajitno. (2012). Konseling Remaja: Intervensi Praktis Bagi Remaja Berisiko. Yogyakarta: Pustaka Pelajar.

Sugiyono. (2007). Metode Penelitian Kuantitatif Kualitatif dan R\&D. Bandung: Alfabeta.

Sujarwni, V Wiratna. (2014). Metedologi Penelitian. Yogyakarta: Pustaka Baru

Syamsu Yusuf dan Juntika Nurihsan, (2005). Landasan Bimbingan dan Konseling, Bandung: Remaja Rosda Karya

Taqizadeh, A., Zare Bahramabadi, M., \& Shafi Abadi, A. (2014). The relationship of social desirability and educational self-efficacy with bullying behavior among female students of middle school in the city of Gonabad. Journal of Research and Health, 4(2), 721-727. 
Teacher's Self-Efficacy in Handling School Bullying: A Case Study. International Journal of English Literature and Social Sciences, 2(4), 187-202. https://doi.org/10.24001/ijels.2.4.23

Thornberg, R., Wänström, L., Elmelid, R., Johansson, A., \& Mellander, E. (2020). Standing up for the victim or supporting the bully? Bystander responses and their associations with moral disengagement, defender self-efficacy, and collective efficacy. Social Psychology of Education, 0123456789. https://doi.org/10.1007/s11218-020-09549-Z

Utami, T. W., Fadilah, A., \& PH, L. (2019). Hubungan bullying dengan ketidakberdayaan pada remaja. Jurnal Keperawatan Jiwa, 7(2), 159. https://doi.org/10.26714/jkj.7.2.2019.161

Wachs, S., Bilz, L., Fischer, S. M., Schubarth, W., \& Wright, M. F. (2018). Students' willingness to intervene in bullying: Direct and indirect associations with classroom cohesion and selfefficacy. International Journal of Environmental Research and Public Health, 15(11). https://doi.org/10.3390/ijerph15112577

Wibisono, Dermawan. (2013). Panduan Penyusunan Skripsi, Tesis \& Disertasi. Yogyakarta: C.V Andi

Widayanti, Costrie G. (2009). Fenomena Bullying di Sekolah Dasar Negeridi Semarang: Sebuah Studi Deskriptif. Jurnal Psikologi Undip,Vol 5, No.2.

Wiyani, N, A,. (2012). Save Our Children From School Bullying. Jogjakarta : Ar-ruzz Media.

Yayasan Semai jiwa Amini (SEJIWA). (2008). Mengatasi Kekerasan Dari Sekolah dan Lindungan Anak. Jakarta: Grasindo.

Zakiyah, E. Z., Fedryansyah, M., \& Gutama, A. S. (2019). Dampak bullying pada tugas perkembangan remaja korban bullying. Focus : Jurnal Pekerjaan Sosial.

\section{Competing interests:}

The authors declare that they have no significant competing financial, professional or personal interests that might have influenced the performance or presentation of the work described in this manuscript. 